INTERNATIONAL JOURNAL OF MULTIDisciplinARY RESEARCH AND ANALYSis

ISSN(print): 2643-9840, ISSN(online): 2643-9875

Volume 04 Issue 09 September 2021

DOI: 10.47191/ijmra/v4-i9-16, Impact Factor: 6.072

Page No.- $1303-1310$

\title{
Education and Social Change: The Basis of Evolution and Development of a Contemporary Society
}

\author{
Suman Mazumdar \\ H.No-33 eidgah embankment road, hatigaon, gauhati - 781038, assam, india, B.Barooah college , gauhati \\ university
}

ABSTRACT: Changes in society are shifts from the accepted way of life, either they are caused by changes in geography, culturale quipment, population structure, or philosophies, or by diffusion or innovations well within community.It is education that has been a chief instrument in bringing about phenomenal changes in all the aspects of society. A country without education produces incompetent policy makers rather than ideal leaders. The administration proves to be pathetic, with increased rate of crimes, corruption, social disorder, violation of- laws, rules, human rights, and so on. In addition, it is impossible for a society to attain a sustainable socio-economic development with zero contribution to human resource development. The paper significantly demonstrates a conceptual and qualitative research in the context of social change and education.

KEYWORDS: social change, factors, material change, non-material change, technology, ethnocentrism, fatalism, moral development, instrumental relativism, interpersonal conformity, universal ethical principle, education commission

\section{INTRODUCTION}

Human societies are dynamic in nature. It keeps on changing its processes and structure from time to time, naturally. Different sociologists view 'Change' as a process, progress, product, an ideology, a means, an end, a problem or a state, which is brought about by an external or internal factor otherwise. Social change, as a sociological term, may be referred to the significant transformation of the socio-cultural structure of a society over a period of time. It is the variations in the mechanisms of the society that takes place either due to social or other external movements. Social change may be slow or rapid. It may be in any form, be it political, cultural, economic, religious, social or educational; each sphere of the society that undergoes change, alters the total structure of that society. According to Francis E. Merrill and H. Wentworth Elbridge, social change means that a significant number of people are engaging in behavior that differ from those they or their immediate forefather have engaged in some time ago.

Social change is the law of universe. In order to understand social change, we have to look back to our primitive societies, which can be basically categorized as- hunting-poaching-and gathering, pastoralism and nomadism, agriculture, industrial and commercial society. It has been through a long way- through phases of evolution and reconstruction.

Earlier, prominent sociologists like Emile Durkheim, Auguste Comte, Karl Marx, Max Weber and Herbert Spencer, attempted to understand the root cause of change that lead to the modern society i.e., Urbanization and Industrialization. They were of a similar view that the changes in human societies can be studied and understood in a generalized manner. Studies and researches based on social change before World War II were primarily concentrated on the macro elements and factors of social change. However, after the war in the late 1950s, it came to be studied and unfolded on a micro-level. Later on, a number of books written by sociologists on social change were published, some of which included"Theory of Collective Behavior" (1962) by Neil Smelser, "The Logic of Collective Action" (1965) by Man cur Olson, "Legitimating Crisis" (1975) by Jürgen Harbermas, "Perspective on Social Change" (1977) by Robert H. Lauer, "The Sociology of Social Change" (1994) by Piotr Sztompka, "Islam, Gender and Social Change” (1998) by J. L. Esposito and Y. Yazbeck Haddad, and many more. Several sociologists have been working on the study of the 'COVID-19' pandemic and 'As Black Lives Matter' protests (2020), which has marked a significant social change recently. 


\section{Education and Social Change: The Basis of Evolution and Development of a Contemporary Society}

\section{Characteristics:-}

Social Change is characterized by the following key features-

1. Social Change is Universal- Every society is dynamic in nature. It is the law of the universe. Societies, whether rural or urban, primitive or modern, industrial or non-industrialized, developed or under-developed, go through changes. The changes may be on a large-scale or small-scale, rapid or slow. That is determined by the nature and organization of the societies in a specific period of time.

2. Social Change is Continuous- With the passage of time, societies sometimes flourish and then declines, and the cycle continues. Social change is a never-ending and natural process. It is unstoppable and inevitable, however, it depends on the members of the society whether to accept or reject those changes. Social changes may or may not be apparently visible depending on its material or non-material form of existence.

3. Social Change may be Material or Non-Material- A society undergoes both material and non-material changes. Material change refer to those changes in the society which include the transformation and development of concrete objects (tangible things) and belongings of people, while, Non-Material change refer to the variation in the mechanism of thought processes of the individuals in the society. For instance, inventions in the scientific and technological field, new fashion trends- clothing, jewelry, hairstyles, etc., construction of buildings, industries, dams, and others are included in material changes. While, thought patterns, ideas, beliefs, attitudes, teaching methods, changes in the educational system, etc. are some of the examples of non-material culture.

4. Social Change may be Short-term or Long-term- The transience of changes in the society is dependent on time. It may take years for a change to show its long-term effects or it may produce sudden or immediate outcomes. Some social changes occur gradually and may endure for a long period of time. Whereas, some changes spread at a fast pace and soon vanish in a short span of time. Permanent social changes include reforms in education, women empowerment, inventions, development in transportation, industrialization, dressing style, migration, etc.

5. Social Change is Multi-Causal- Change may have effect on one aspect of the society but the cause of the effect is multidimensional. That implies change is not the product of a single factor. Rather, it generates from various physical, demographical, biological, cultural, social and economic factors. All the mechanisms of the social structure operates as an integrated whole, and are therefore, inter-related and codependent.

6. Social Change may be planned or unplanned- Social changes may be either planned or unplanned. Planned social changes refer to those changes that takes place naturally and without any prior warning or unexpected call. These changes occur suddenly or accidentally at a particular time. For example, changes occurring as a result of certain decisions, natural calamities such as earthquakes, floods, volcanic eruptions, famines, pandemics, etc. The society has no control over the course and level of these social changes.

Planned social changes may be referred to those changes which are governed by human actions. These preferably take place from prior planning and efforts. Government plans and programmes, policies, redesigning of curriculum, and so on are some of the instances of planned changes.

7. Social Change Produces a Sequence of Reaction- Social change creates a chain of reaction, in the sense that, change in one aspect of society incites changes in its other sections as well. In other words, when a fragment of society undergoes transformation, it leads to changes in various other dimensions. As an example, change in the status of women has led to the encouragement of women and girl education, equal wages and job opportunities, family relationships, economic status of the family, and many more. Other significant examples include the abolition of slavery and untouchability that led to the development of fundamental human rights.

8. Principle of Uncertainty- Changes in society are ambiguous in nature. Although, predictions are made in some cases, they cannot be ascertained. This is due to the fact that social change is dynamic and not uniform. Based on the nature of the society, it may be high or low, and slow or rapid. For instance, the pace at which the structure of rural society changes is much less and slower than urban society. The speed of alteration cannot be regulated by humans, and hence, it is uncertain.

\section{Factors or Agencies of Social Change:-}

Social change is universal and continuous. Every society goes through some kind of transformations and developments. But why do changes occur in societies? What are the factors or agencies of social change? Let us study in detail the key factors responsible for changes in society. 
Education and Social Change: The Basis of Evolution and Development of a Contemporary Society

FACTORS OF SOCIAL CHANGE

\begin{tabular}{|l|}
\hline Geographical or Physical factors \\
\hline Demographical factors \\
\hline Biological factors \\
\hline Economic factors \\
\hline Cultural factors \\
\hline Technological factors \\
\hline Psychological factors \\
\hline Ideological factors \\
\hline
\end{tabular}

1. Geographical or Physical factors- The geographical structure plays a crucial role in the social, cultural, economic and political aspects of society. It includes the land, forests, mountains, rivers, flora and fauna, and the climate, of a particular region. These factors are greatly responsible for bringing social changes. Geographical changes can mainly be categorized as natural and man-made. Variations take place in the physical structure of a particular region due to natural phenomenon such as earthquakes, droughts, floods, tsunamis, cyclones, etc. These change stake place naturally without human interventions.

On the other side, there are certain human activities that bring about changes in the geography of a particular region. Human intervention in nature consequently leads to alteration in the social structure. Such as exploitation of resources, deforestation on a large scale, have adversely affected the environment contributing to soil erosion, climate change, as well as affecting animal life. Pollution caused by vehicles, industries and burning of fossil fuels has deteriorated the quality of air and water which are the ultimate needs for life to survive on earth. 'The Bhopal Gas Tragedy' of 1984, the 'Vishakhapatnam Gas Leak' and 'Vizag Gas Leak' of 2020, the 'Baghjan Gas Tragedy' of 2020, etc. are some of the significant examples of geographical factors of social change.

2. Demographical factors- The term 'Demography' has been derived from two Greek words 'Demos' and 'Graphs'. 'Demos' mean 'People' and 'Graphs' mean 'to draw or write'. Hence, etymologically, Demography is the statistical and scientific study of human population- its structure, composition, size, density, distribution and the processes of population change. Suppose, change in the composition of population i.e. sex ratio simultaneously changes the composition of society. This creates an imbalance as the number of females is more than the males, and vice versa. Likewise, more number of children implies slow rate of increase in population, while more number of adults may lead to high rate of increase in population.

High Fertility Rate and Low Mortality Rate means a high population growth, while Low Fertility Rate and High Mortality Rate means a low population growth. Other factors such as child marriage, poverty, widow marriage, preference for sons, polygamy and migration determines the popOulation growth that may bring drastic changes in the overall structure of society. A fine example may be of the 'Indo-Pakistan Partition' in 1947, which greatly influenced change in the structure and organization of the societies.

3. Biological factors- Biological factors refer to those factors related to the genetic constitution of living beings. It includes both human and other living organisms like plants, animals, insects, birds, etc. Both are mutually dependent on each other. Human beings need the other living beings to satisfy their basic requirements such as food and clothing. Any amount of increase or decrease in the population of non-human beings affects the society and influence change. At the same time, increase or decrease in the human population, certainly brings about social change. 


\section{Education and Social Change: The Basis of Evolution and Development of a Contemporary Society}

According to Italian sociologist Vilfredo Pareto, "biological evolution of mankind brings social changes." For example, individuals belonging to the upper class of society possess instincts that are inherited from the older generation of their family. Thus, the nature and behavior of humans influence social change. Similarly, age and sex composition also determines social change. A balance must be made in the sex ratio to create balance in the society. Moreover, if the aged population is higher than the young age group, economic growth of the society is hindered. In contrast, if the aged population decreases, the younger generation lacks guidance and wisdom of life. For instance, the human genetic character is totally different from that of non-human beings. They are more rational, capable and potential because of which, they influence social change and promotes socio-cultural development.

4. Economic factors- One of the significant aspect among economic factors is industrialization. Industrialization has brought about a revolutionary change in the whole system of society. The rate of production in primitive societies, was comparatively minimum than today's modern industrial society. The rise of capitalism has generated a rapid increase in manufacture and production, and makes sure to constantly update its methods and technologies.

The change in status of women also plays a vital role in influencing changes in the society. In the modern day society, women are more empowered and they can be found working in different economic sectors, be it primary, secondary or tertiary, thereby contributing to the economic growth as well as bringing significant social changes. The period of 'Industrial Revolution' (1760-1840) may be regarded as a notable example of economic factors of social change.

5. Cultural factors- Sociologically, 'Culture' is referred to an acquired or shared pattern of behavior, which is preserved and transferred from one generation to the other. It includes the modes of behavior, norms, customs, traditions, beliefs, ethics, religion, and so on. There exist a close relation between all the elements of culture and the society. Therefore, change in any aspect of culture directly or indirectly influences the social processes and organization.

Changes in the culture of a society occur by two ways- (a) y discovery and inventions, and (b) by borrowing (diffusion). The former originates from the society itself, and the latter originates from the culture of another society. One such instance is the study of religion by German sociologist, Max Weber. In his book "The Protestant Ethic and the Spirit of Capitalism", published in 1930, he explained the change and development of capitalist society with regard to religious factors which, when combined together with other factors- economic, social and political, produces change in society. Another example may be the attitude towards sex which was formed by the Catholics in the medieval period is still prevalent in the $21^{\text {st }}$ century.

6. Technological factors- According to Karl Marx, technology is the main source of social change. The modern age is regarded as the 'Age of Technology'. Any new invention or discovery makes a great impact on the society. From a broader sociological perspective, technology is referred to as a systematic organization, management, utilization and application of scientific knowledge to fulfill human needs. There are three forms of technological factors responsible for social change viz. (a) Technological inventions and discoveries, (b) Production technology and (c) Transportation and Communication.

William F. Ogburn is of the view that technology is transforming society by changing the world to which we turn. This adjustment is generally made in the material world, and the adaptation we make to these changes also alters traditions and social structures. Technological factors of social change may be negative or positive, and destructive or productive depending upon its utility. The 'Atomic bombings of Hiroshima and Nagasaki' in 1945, the 'World War Trade Center Terror Attack' in 2001, 'Assam Bombings' in 2008, etc. are some of the examples of technological factors that have caused negative changes in the society. However, technological developments in the field of education, sports, entertainment, mass media and politics, has positively influenced the society that has proved to be landmark in bringing about changes in our lives.

7. Psychological or Ideological factors- Humans, as social beings, love change. They are always on the quest for new knowledge, ideas and experiences. A number of sociologists believed that social change is profoundly influenced by psychological factors. As individuals are introduced to the norms, traditions, customs, mores, folkways, beliefs, values, etc. of the society, they develop those skills after rationally analyzing and evaluating them. The society decides whether to accept and conform to those social norms, or to disregard them and bring changes, for the development and upliftment of society. Like the 'Abolition of Sati Pratha' (1829) and 'Abolition of Untouchability' (1950), Abolition of 'Polygamy' (India, 1956) and 'Triple Talaq Bill' (2019) are some of the salient examples of the effect of psychological factors of change in society. 


\section{Education and Social Change: The Basis of Evolution and Development of a Contemporary Society}

Hence, these age-old customs, traditions and beliefs are no longer practised (except in few rural backward areas where it still exists). This new outlook and ideology of the present society is the result of revolutionization, modernization, and development in the field of science and education.

\section{Causes of Social Change}

Social change is multi-causal, which means, it is not caused by a single factor. Changes in society takes place due to several causes all the aspect of it is interwoven. The following conclusions can be made from the factors of social change-Changes occur due to geographical, physical or environmental factors. These may be natural (earthquakes, floods, droughts, tsunamis, landslides, etc.) or through human activities (deforestation, pollution, agricultural activities, fishing, exploitation of natural resources, etc.)

1. Changes occurring in the society depend upon its demographic structure- age and sex composition, population size, density, distribution and processes. High birth and death rates, marital status, sex ratio, social movements and migration (Internal, External, In-migration, Out-migration, Gross migration, Net migration, Immigration and Emigration) generate social change.

2. Social changes also occur due biological causes. It points out the fact that humans and non-humans are inter-linked and inter-dependent. However, it is needless to say that humans, as rational beings, are more intelligent, potential and capable to bring about social change.

3. Economic factor is one of the significant causes of social change. Globalization, Industrialization, World Trade Organization, etc. are some of the remarkable events in the field of economy that influenced changes in the society.

4. Cultural change as one of the key aspects of society, may occur in three main forms- Discoveries, Inventions and Diffusion. Cultural values and ethics may exist in physical, mental, psychological or spiritual.

5. Social change is also caused due to technological factors. Technological changes may be productive or destructive. These are divided into three main categories-

a) Technological inventions and discoveries

b) Production technology

c) Transportation and Communication

6. Changes in society may be caused by idealistic or ideological factors such as values, beliefs, ideals and ideologies. These factors are decisive in nature,that gives shape and direction to a society.

\section{Factors Resisting Social Change}

In countries like India, the structure of society has its traditional roots and is not easily flexible to changes. There are certain old traditions, customs and values that a society finds difficult to relinquish. Hence, they resist to changes. To bring and accept changes in the society is a challenging task. The process of change involves disorganization and reorganization of the whole social structure. In whatever way, change in society is inescapable. Now, let us discuss about some of the dominant obstacles that hinders social change.

\section{Social factors-}

1. Vested Interests- Society is constituted of individual differences among its members. Amidst those, there are individuals or groups who are more concerned about the influence of change on their power, position and prestige. The fear of losing control over their gains, often resist change. One notable incidence is the policy of independence of Muslim women against men, declared by the Union of Soviet Socialist Republics (USSR), which was resisted by the clergy, who showed their wrath against women participating in the 'red scarf' movement, killing hundreds.

2. Ideological Resistance- Ideology is a system of ideas and ideals related to political, cultural, economic, religious and social beliefs. These are sometimes disregarded and opposed, which is known as Ideological Resistance. Such example is of reformers like Mahatma Gandhi and B. R. Ambedkar, who condemned the idea of caste-system and untouchability. They believed it to be a crime and social evil in the name of Hinduism and therefore, the 'HarijanSevakSangh' was established in 1932. However, this change was severely resisted the Hindu upper caste society.

3. Social Class- The structure of societies, especially in the earlier days, was hierarchical and authoritarian. There was a division among the upper class, middle class (also known as working class) and lower class, where the members belonging to the higher class of society exploits the poor or the lower section of the society. Hence, they resist change for the fear of losing their status or privilege. For instance, in the Feudal society, the Zamindars and Jagirdars (landlords) ruled over the serfs or peasants (workers and labors who were bound to their landlords). So they resisted the end of feudalism. 


\section{Education and Social Change: The Basis of Evolution and Development of a Contemporary Society}

4. Organized Opposition- The term 'Organized Opposition' in sociology, refer to the resistance on the part of a group of individuals by influencing the change through social movements. Consider the example of the 'Chipko Movement or ChipkoAndolan' of 1973 in Uttarakhand, led by SundarlalBahuguna. The movement was started to conserve the forests and protest against the Forest Department, who cut down trees on a large scale for commercial purposes.

\section{Economic factors-}

1. High Costs- Resistance on social change bears from high investment requirements on the part of industrial companies, institutions and organizations, and the state government. Therefore, high costs often become an obstacle for changes to occur in society. Such as firms and manufacturing companies find it difficult to pay for the protection of environment and workers, according to the policies and protocols set up by the government. So, they often carry out business in an illegal way.

2. Cost Distribution and Benefits- The economic disparity between the rich and poor promotes resistance on social change. To give an idea, the rich section of society that enjoys high benefits while the poorer section is deprived of it, resist changes that may affect their wealth or status. For example, in a federal government, the cost of education in educational institutions is increased in order to gain more benefit. Hence, they resist any changes that interfere in their regulation system.

\section{Cultural factors-}

1. Ethnocentrism- 'Ethnocentrism' in sociological terms, refer to the belief of intrinsic superiority of one's culture or ethnic group. In other words, it is a biased attitude, where individuals strongly regard their culture and way of living the utmost appropriate and better than that of others. Ethnocentrism is characterized by sense of conceit, pride, dominance, unjustness, disrespect and ignorance. Hence, the ethnocentric attitude is of the reasons for resistance on social change. As in many parts of the world, the 'Whites' consider themselves superior, and therefore, are indifferent and refuse to accept people of other races or ethnicity, especially the 'Blacks'.

2. Superstitious Beliefs and Reverence for the Past- Changes in society are restrained by beliefs that are not established on authentic or proved facts. Some societies hold great reverence for the old traditional beliefs and values, which are still prevalent. Denial of discarding their old ways and adopting the new, resist social changes. Such as, presence of widows in auspicious occasions is considered to be inauspicious, avoiding of consuming eggs by women in Zimbabwe as they believe that it causes infertility, and many other health issues.

3. Fatalism- Fatalism is a social as well as philosophical attitude, which holds the belief that human beings are powerless in conditioning change and surrenders events to fate; change is unavoidable destiny and is bound to happen on its own. This outlook hinders change and development in the society. For example, some cultures believe that the use of fertilizers to increase productivity of crops is a vain attempt, considering that God causes everything and it is beyond human control.

\section{Psychological factors-}

1. Customs and Habits- Customs are shared pattern of behavior or norms of action. These are established habits in a society. Customs have nothing to do with social control; it is completely dependent on individuals to follow or reject them. However, it becomes difficult to replace accustomed habits, values and ways of living. Thus, social change is hampered. As in case of Orthodox families, the members are not much receptive to the modern way of living, be it regarding the religious beliefs and ideas, or accepting the scientific and technological world.

2. Ignorance and Fear of the New- Ignorance is characterized by preconception, biasness and fear of the new. It is natural for humans to be worried about new changes since change is unpredictable. The doubt and fear for the consequences of change, refrains the society from making decisions and influencing change. For example, in the past, education for girls and women was not encouraged. But, after the change in the roles and status of women, the society's outlook completely changed.

3. Development of Morality-Moral Development or Moral Reasoning refers to the process wherein individuals develop proper attitudes and social behavior, forming a sense of what is right and wrong. Lawrence Kohlberg, in 1958, gave a comprehensive theory of moral development. The theory constituted of three levels of six stages:

a) Pre-Conventional Level- This level of moral development generally exists in the basic or elementary level up to the age of ten years. It involves accommodating and responding to the needs and escaping punishments. The pre-conventional level is divided into two stages-

Obedience and Punishment Orientation- In the first stage, individuals are introduced to the rules and regulations, and are taught to respect elders, by a superior or person in authority (seniors, teachers and parents). An act of wrong doing is punished accordingly. Therefore, being obedient towards the rules imply avoiding punishment. 


\section{Education and Social Change: The Basis of Evolution and Development of a Contemporary Society}

Instrumental Relativism- The second stage is also known as 'Individual, Instrumentation and Exchange Stage'. It is characterized by moral reciprocity. Here, an individual is least concerned about the needs of others. Instead the child follows the rules only to the point where it benefits him/her. This stage may be said to be governed by equitable justice. In some cases, children make deals or negotiate with each other or with adults, where they agree to act obediently, in return for a reward or compensation.

b) Conventional Level- The Conventional level begins at around the age of 10 and lasts till adulthood, and all throughout the life. It is featured by conformity to the social norms and order. It is characterized by conformity to the social norms and order. This level is further divided into-

Interpersonal Conformity- In this stage of moral development, individuals adapt and stick to the norms and rules set by the authority, and put efforts to meet social expectations. Children act in accordance to what the society says to be right and wrong, not because of fear of punishment, but they recognize it to be necessary in order to maintain positive social relationships. Conformity to social norms and rules originate from the desire to be in the good list.

Law and Order Orientation- This is the fourth stage of moral development, where individuals abide by the laws and rules as they are essential for the smooth functioning of society. The whole society is taken into consideration while maintaining social law and order. These are regarded the foundation that determine all actions. Individuals are obliged to do their duty, obey the rules and respect authorities. This stage is also called the 'Social system and Conscience Stage'.

c) Post-Conventional Level- The Post-Conventional Level is based on abstract reasoning of principles and values. Individuals think past conventional morality, and conform to morality based on reasoning, analyzing and examining those norms and values. Here, moral evaluation of an act on the part of the individual takes place rather than social conventions. Individuals decide whether the laws are just or unjust and whether to follow or eliminate them. There are two stages in this level:

Social Contract Orientation- The fifth stage is also called the 'Individual Rights Stage'. It is featured by correct behavior. The world is comprised of individuals with diverse thoughts, ideas, values, rights and opinions. Each should be respected by its members of social groups. Individuals recognize the norms to be relative to the social groups. Laws, at this stage, are considered as 'Social Contracts', in contrast to fixed laws and orders.

Universal Ethical Principle- In the sixth and the last stage, individuals determine the validity of social laws, keeping in account the basic universal human rights- equality, justice, liberty, dignity and respect. This stage is governed by the conscience of individual that rises above the social, cultural and religious norms or conventions. It is also known as the 'Principled Conscience Stage'.

\section{Education as an Instrument of Social Change}

Education is regarded as one of the most significant, powerful and effective agencies of social change and development. Social change may be referred to the alteration, transformation or variation in the different aspects of society i.e. economic, cultural, social, political, technological, religious, etc. In the historical times, education was considered to be only a medium to influence social control and produce responsible citizens. At that time, education hardly emphasized on bringing social changes.

However, things are different now. Education holds a tremendously different impression on society. With the passage of time, societies have gone through huge transformations in several phases. According to Nelson Mandela, education is the most powerful weapon which you can use to change the world. With the emergence of globalization, modernization, urbanization and industrialization, humane society's intellect have shifted to adapt to the rapid change.

According to Prof.V.R. Taneja, education basically functions at three levels-

a) Preservation of culture

b) Transmission of culture from one generation to the other.

c) Dissemination of new knowledge keeping in view the already existing culture.

Education has contributed to a significant change in women's lives as well. They are more educated and empowered. They can make decisions involving the family and the home. Women are found in different employment sectors and have a greater contribution to nation building. As they are more educated, they also play a major role in the control of the population. As a result, women are now viewed beyond a housewife. The objective of education is to influence change in individuals and their lifestyles. It has helped remove superstitions and practices in society. Such as in Africa, where female genital mutilation which was known to be harmful to health as well as life threatening, was a social norm. But after the rise of an educated society, such practices were abandoned. Education helps in changing the attitudes and approaches toward the 


\section{Education and Social Change: The Basis of Evolution and Development of a Contemporary Society}

loopholes in various aspects of the social system. It develops knowledge, understanding and skills in individuals that contribute to the development of the society. Peter Drucker opines that a highly educated man has become the core resource of contemporary world, and the availability of such men is the major determinant of his economic, military and even political ability.

The modern age is regarded as the 'Age of Science and Technology', where discoveries and inventions have brought radical changes in societies on a global platform. Researches in the field of science and technology, development of transportation and communication, mass media, digitalization, information and communication technology (ICT), manufacture of new gadgets, etc. are all products of the modern education. In regardto education as a medium of social change, the Education Commission of 1964-66 stated that there is one tool, and only one tool, that can be used if this change on a large scale is to be achieved without violent revolution (and even then it would still be necessary), that is education. Other agencies may help, and may indeed sometimes have a more apparent impact. But the national education system is the only instrument that can reach out to all people. It is not, however, a magic wand to wave the desires into existence. It is a tricky instrument whose effective use takes strength of will, dedication of effort and commitment. But it is a thoroughly tested instrument that has served nations well in their struggle for growth.

\section{METHODOLOGY}

This article is based on theoretical knowledge of qualitative secondary data with a purely conceptual and analytical approach. The paper has employed a standard pattern of classification, analysis and evaluation of thesis and notions, highlighting the distinction and liaison between social change and education. The desk study involve collation of data in order to encapsulate knowledge concerning the shifting phenomena in the social structure andinfluence of education in those aspects. Usage of primary books, secondary textbooks and other authentic official sources were the supporting elements in the development of this paper.

\section{CONCLUSION}

Education is the root cause of all the changes taking place in society. These changes initially begin at the level of the unconscious, but are eventually transferred to and embraced at the conscious level, after which the changes become socially appropriate. Education, here, works in two phases- firstly, it prepares an individual to accept social change. It generates disagreements, dejections and frustrations in the minds of individuals regarding those aspects which are subjected to criticism, and make them capable of accepting those changes. Education introduces members of the society to the inefficiency and shortcomings of the existing functions and organization of the society. Thereby, it helps the society in developing an urge to bring the desired social changes. Secondly, education not only prepare individuals for accepting and welcoming change, but also aims to make them able, skillful, efficient and productive to bring about those changes in the society at the level of consciousness. To give an example, education in Ancient Greece was responsible in bringing together a number of thinkers and reformers, who brought in discoveries, inventions and even public laws which are still in practice.

\section{REFERENCES}

1. Merrill, F. E.,\&Eldredge, H.W., Culture and Society: An introduction to sociology, New York: Prentice-hall, 1952

2. Smelser, N. J., Karl Marx on Society and Social Change,University of Chicago Press (New Edition), 1975

3. Duncan, O. D.,WilliamF. Ogburn on Culture and Social Change,University of Chicago Press (New Edition), 1965

4. Pathak, S., The Chipko Movement: A People's History, Permanent Black (Orient Blackswan), 2020

5. Bizumic,B., Ethnocentrism: Integrated Perspectives, Routledge ( $1^{\text {st }}$ Edition), 2018

6. Kohlberg, L., The Philosophy of Moral Development, New York: Harper\& Row,1981

7. Taneja, V. R., Socio-Philosophical Approachto Education,Atlantic Publishers \&Distributors Pvt. Ltd, 2005

8. Drucker, P. F., The Age of Discontinuity: Guidelines to Our Changing Society, Routledge (2 ${ }^{\text {nd }}$ Edition), 1992

9. Govt., India, Report of the Education Commission 1964-66,Ministry of Education: Government of India Press, 1966 